\title{
Effect of the pyrolysis atmosphere on the mechanical properties of polymer-derived SiOC and $\mathrm{SiCN}$
}

\begin{abstract}
Gian Domenico Sorarù̀ ${ }^{1}$
Nicola Pugno ${ }^{2,3}$

Consuelo Tavonatti ${ }^{1}$

Mattia Biesuz ${ }^{1}$

Abstract

Mechanical properties of polymer-derived ceramics are usually measured on samples pyrolyzed in inert atmosphere. Here, we report the hardness and elastic modulus of $\mathrm{SiOC}$ and $\mathrm{SiCN}$ pyrolyzed in both inert $(\mathrm{Ar})$ and reactive $\left(\mathrm{CO}_{2}\right)$ atmosphere The external surface of the specimens exposed to the pyrolysis gas was characterized by Vickers microhardness measurements and infrared spectroscopy. The elastic modulus was evaluated by three-point bending tests on thin (150-200 $\mu \mathrm{m})$ and dense specimens. Polished sections of the SiOC samples were prepared to study, by energy-dispersive X-ray spectroscopy (EDXS) and nanoindentation, how the elemental composition, hardness, and elastic modulus vary from the surface toward the bulk. For both compositions, pyrolysis in $\mathrm{CO}_{2}$ leads to a strong decrease in the hardness and elastic modulus. The hardness of both the samples pyrolyzed in $\mathrm{CO}_{2}$ approaches the typical value for fused silica, suggesting that $\mathrm{CO}_{2}$ selectively breaks the $\mathrm{Si}-\mathrm{C}$ and $\mathrm{Si}-\mathrm{N}$ bonds and leads to the formation of a silica-like network. EDXS and nanoindentation reveal that the modification induced by the $\mathrm{CO}_{2}$ flow extends below the surface at least for a thickness of about $30 \mu \mathrm{m}$.
\end{abstract}

\section{K E Y W O R D S}

$\mathrm{CO}_{2}$, mechanical properties, polymer-derived ceramics, $\mathrm{SiCN}, \mathrm{SiOC}$

${ }^{1}$ Glass \& Ceramics Laboratory, Department of Industrial Engineering, University of Trento, Trento, Italy

${ }^{2}$ Laboratory of Bio-inspired, Bionic, Nano, Meta Materials \& Mechanics, Department of Civil, Environmental and Mechanical Engineering, University of Trento, Trento, Italy

${ }^{3}$ School of Engineering and Materials

Science, Queen Mary University of

London, London, United Kingdom

\section{Correspondence}

Gian Domenico Sorarù, Glass \& Ceramics

Laboratory, Department of Industrial Engineering, University of Trento, Via Sommarive 9, 38123 Trento, Italy.

Email: giandomenico.soraru@unitn.it

Funding information

Italian Ministry of Education, University and Research (MIUR), Grant/Award Number: PRIN-20177TTP3S and

PRIN2017 - 2017PMR932; Fondazione

Cassa Di Risparmio Di Trento E Rovereto;

\section{1 | INTRODUCTION}

Polymer pyrolysis is a well-established soft chemistry route for the synthesis of advanced ceramics in the $\mathrm{Si}-\mathrm{C}-\mathrm{N}-\mathrm{O}$ system. ${ }^{1,2}$ These materials, known as polymer-derived ceramics (PDCs), have shown unique mechanical and functional properties and have been proposed for different application in many fields..$^{3-9}$ The vast range of processing techniques which can be applied to this family of ceramics has led to the fabrication of a multitude of shapes such as fibers, thin films, porous components (foams wiopen/closed cell, aerogels), 3D printed lattices and objects, microelectromechanical systems (MEMS), etc. ${ }^{10-19}$

Among the most striking features of this process is the possibility to fabricate, at a relatively low temperature $\left(1000^{\circ} \mathrm{C}\right.$ $1400^{\circ} \mathrm{C}$ ), silicon oxycarbides ( $\mathrm{SiOC}$ ), and silicon carbonitrides $(\mathrm{SiCN})$ ceramics which display elastic modulus, hardness, and creep resistance similar or even better than the corresponding materials sintered (such as $\mathrm{Si}_{3} \mathrm{~N}_{4}$ or $\mathrm{SiC}$ ) or melted (vitreous silica) at much higher temperature. ${ }^{20,21}$ Accordingly, silicon oxycarbide glasses pyrolyzed at $1000^{\circ} \mathrm{C}$ display elastic modulus, 
hardness, and viscosity which are well above those reported in the literature for silica glass, and amorphous silicon carbonitride has shown the highest viscosity reported for an amorphous ceramic so far.22,23

Researchers have tried to correlate the exceptional mechanical properties of amorphous SiOC and SiCN to their nanostructure and to their chemical composition. Typically SiOC and SiCN PDCs consist of an amorphous phase in which $\mathrm{Si}-$ $\mathrm{O} / \mathrm{Si}-\mathrm{C}$ and $\mathrm{Si}-\mathrm{N} / \mathrm{Si}-\mathrm{C}$ bonds exist together with a free carbon phase. ${ }^{24-27}$ Incorporation of tetravalent $\mathrm{C}$ sites into $\mathrm{SiO}_{2}$ increases the network connectivity and accordingly silicon oxycarbide glasses have shown improved hardness $(H)$, Young's modulus $(E)$, and viscosity $(\eta)$. Moreover, it has been shown that the $H, E$, and $\eta$ increase with $\mathrm{Si}-\mathrm{C}$ bond density, whereas hardness and Young's modulus decrease by increasing the volume fraction of free carbon. ${ }^{3,28-30}$ As for the SiCN system, studies in the literature report the hardness, elastic modulus, and viscosity for few selected compositions and no papers have been found dealing with the role of chemical composition or amount of free carbon phase. ${ }^{20,31}$

So far, the properties of PDCs have been studied on materials obtained through pyrolysis in inert atmosphere. Recently, a work from Narisawa's group ${ }^{32}$ showed that one of the most studied precursor, polymethylsilsesquioxane $\left(\mathrm{CH}_{3} \mathrm{SiO}_{1.5}\right)$, leads to silicon oxycarbide glass upon pyrolysis in inert atmosphere (Ar), whereas it converts into a SiOC glass with no $\mathrm{Si}-\mathrm{C}$ bonds when pyrolyzed in reactive $\mathrm{CO}_{2}$. Essentially, pyrolysis in Ar leads to a nanocomposite consisting of $\mathrm{SiOC} / \mathrm{C}_{\text {free }}$ phases, whereas in $\mathrm{CO}_{2}$ the final material is a $\mathrm{SiO}_{2} / \mathrm{C}_{\text {free }}$ nanocomposites (because the $\mathrm{Si}-\mathrm{C}$ bonds are converted into $\mathrm{Si}-\mathrm{O}$ bonds). Interestingly, the nanostructural features of the two SiOC glasses, $\mathrm{Ar} v \mathrm{CO}_{2}$, seems quite similar in terms of size, distribution, and amount of the free carbon, being the composition of the amorphous network which is, in one case (Ar atmosphere) built up by $\mathrm{Si}-\mathrm{O}$ and $\mathrm{Si}-\mathrm{C}$ bonds and in the other $\left(\mathrm{CO}_{2}\right.$ atmosphere) only by $\mathrm{Si}-\mathrm{O}$ bonds. ${ }^{32,33}$

We decided to build on these results and measure mechanical properties of $\mathrm{SiOC}$ glasses obtained in $\mathrm{Ar}$ and $\mathrm{CO}_{2}$ atmosphere. Similarly, we also prepared and studied, after the same pyrolysis processes, SiCN PDCs. In this case, the reactive pyrolysis in $\mathrm{CO}_{2}$ was never reported before and the measurement of the mechanical properties could offer a first clue on the reactivity of carbon dioxide during pyrolysis of polysilazanes.

\section{2 | EXPERIMENTAL DETAILS}

\section{1 | Synthesis}

Commercially available liquid polysiloxane (SPR-036, Starfire System ${ }^{\circledR}$ ) and polysilazane (Durazane 1800; CAS\#: 50359070-3; Merck Performance Materials GmbH, Wiesbaden, Germany) were used as received and crosslinked with divynilbenzene (DVB, CAS: 1321-74-0, SigmaAldrich) via a Pt-catalized hydrosilylation reaction between the Si-H groups of the Si-polymers and the $\mathrm{C}=\mathrm{C}$ groups present on both the cross-linker and the preceramic polymers. ${ }^{34,35}$ Platinum-divinyltetramethyldisiloxane complex in xylene, with Pt content of $\sim 2$ wt\% (Karstedt's catalyst, CAS: 68478-92-2, Sigma-Aldrich) was further diluted to obtain a solution containing $0.1 \mathrm{wt} \%$ of catalyst. Acetone was used as solvent (CAS\#: 67-64-1; >99\% pure, Sigma-Aldrich).

The reagents were always mixed using the following recipe: $1.5 \mathrm{~g}$ of the liquid silicon polymer (SPR-036 or Durazane), $1 \mathrm{~g}$ of acetone, $0.23 \mathrm{~g}$ of DVB were added in this order into a beaker and homogenized for 5 minutes by magnetic stirring. Then $150 \mu \mathrm{L}$ of Pt-catalyst was added and the solution stirred for additional 2 minutes before pouring into the molds to obtain the thin films. To fabricate the molds, a Mylard film was glued on a rectangular $\left(6 \times 6 \mathrm{~cm}^{2}\right)$ and plane block of plexiglass. Then, the edges of the Mylard film were folded up to form the mold walls. The amount of solution prepared and the area of the mold were optimized to get a thickness of the liquid film of about 200-400 $\mu \mathrm{m}$. After casting, the molds were kept open at room temperature under a fume hood for drying and cross-linking. Typically, SPR-036- and the Durazane-based samples were ready to be handled for the subsequent operations after 1-2 days and 4-5 days, respectively. Disks samples were finally cut with a punch die of 22, 12 , and $10 \mathrm{~mm}$ in diameter.

\subsection{Pyrolysis process}

Pyrolysis was performed using an alumina tubular furnace (Lindberg Blu). The preceramic disks were placed into an alumina crucible. The gas flow (Ar or $\mathrm{CO}_{2}$ ) was set at $200 \mathrm{~mL} \mathrm{~min}^{-1}$. The $\mathrm{CO}_{2}$ pyrolysis cycle (Figure 1) started with a purging step of 5 hours at room temperature, then the temperature was increased at $2^{\circ} \mathrm{C} \min ^{-1}$ up to $800^{\circ} \mathrm{C}$ and hold for 1 hour. Then, the temperature was decreased at $5^{\circ} \mathrm{C} \mathrm{min}^{-1}$ down to $500^{\circ} \mathrm{C}$ and immediately the gas flow was switched from $\mathrm{CO}_{2}$ to $\mathrm{Ar}$. The samples were maintained at $500^{\circ} \mathrm{C}$ for 4 hours to allow the purging of the furnace from $\mathrm{CO}_{2}$ to $\mathrm{Ar}$. We believe that during the 
purging step at $500^{\circ} \mathrm{C}$ the nanostructure formed at $800^{\circ} \mathrm{C}$ do not change. Then, the temperature was increased, $2^{\circ} \mathrm{C} \mathrm{min}{ }^{-1}$ up to $1200^{\circ} \mathrm{C}, 1$ hour hold and finally cooled down to RT at $2^{\circ} \mathrm{C} \min ^{-1}$. For the Ar pyrolysis the same cycle was adopted but, of course, Ar flow is used through the whole treatment. The rationale for using this pyrolysis cycle, in which the reactive $\mathrm{CO}_{2}$ atmosphere is maintained only up to $800^{\circ} \mathrm{C}$, is the following: from the literature ${ }^{32}$ is known that the reaction between $\mathrm{CO}_{2}$ and the polysiloxane occurs up to $\sim 800^{\circ} \mathrm{C}$. Above this temperature, due to the Bouduard equilibrium, $\mathrm{CO}_{2}+\mathrm{C}=2 \mathrm{CO}, \mathrm{CO}_{2}$ starts to consume $\mathrm{C}_{\text {free }}$ present in the $\mathrm{SiOC}$. If the pyrolysis in $\mathrm{CO}_{2}$ atmosphere had been extended up to $1200^{\circ} \mathrm{C}$, it would have resulted in the formation of silica with a lower, or even negligible, amount of free carbon. In our opinion,
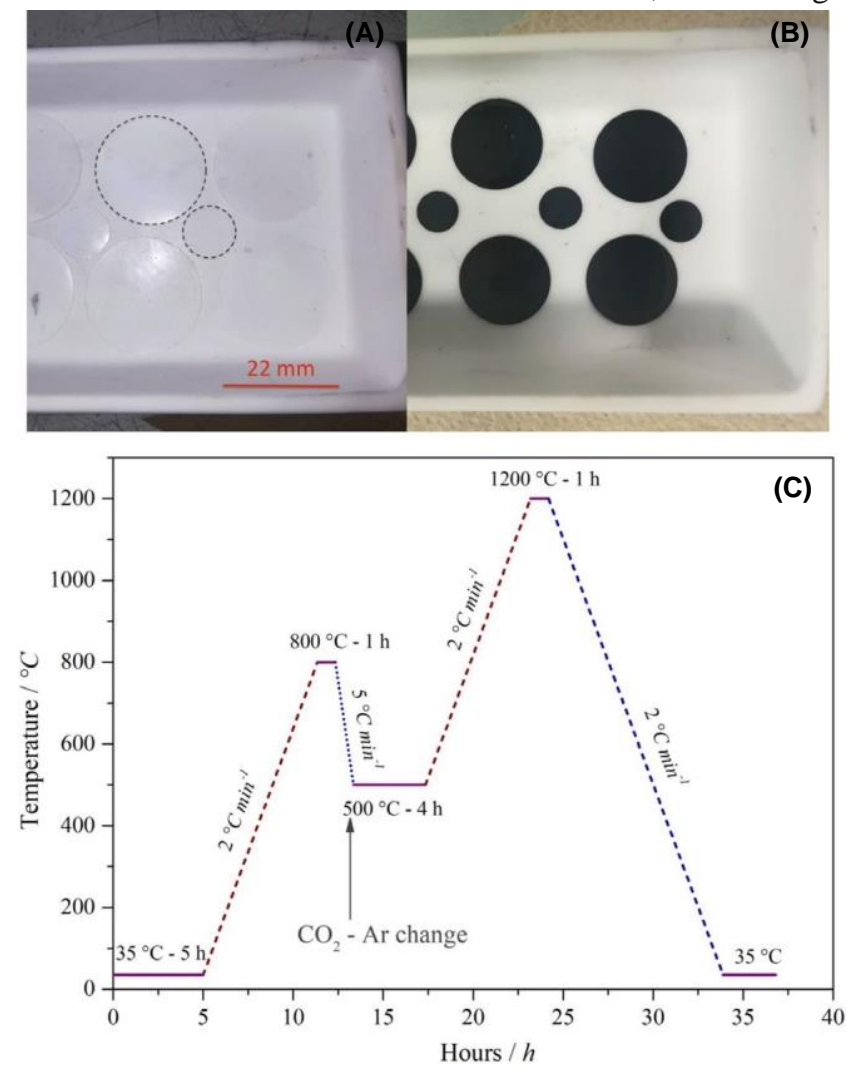

FIGURE 1 (A) Typical disk samples ready to be pyrolyzed, (B)

$\mathrm{SiOC}$ samples after pyrolysis in $\mathrm{CO}_{2}$ flow, and (C) pyrolysis cycle [Color figure can be viewed at wileyonlinelibrary.com]

the selected pyrolysis cycle (Figure 1) should form, at $800^{\circ} \mathrm{C}$ the expected $\mathrm{SiO}_{2} / \mathrm{C}_{\text {free }}$ network and the further pyrolysis up to $1200^{\circ} \mathrm{C}$ in Ar should complete the ceramization process, removing eventually the transient porosity, leading to a dense SiOC material and not altering the $\mathrm{SiO}_{2} / \mathrm{C}_{\text {free }}$ ratio existing at $800^{\circ} \mathrm{C}$.

\section{3 $\mid$ Characterization techniques}

The weight loss and the shrinkage occurring during the pyrolythic transformation were measured by weighting the disks with an analytical balance (sensitivity $\pm 0.1 \mathrm{mg}$ ) and measuring their diameter with a caliper (sensitivity $\pm 0.01 \mathrm{~mm}$ ) before and after the heat treatment. The density of the pyrolyzed materials was measured by Archimedes method using an analytical balance Gibertini (sensitivity $\pm 0.1 \mathrm{mg}$ ) and following the ASTM C 830 standard.

The chemical bonds in the ceramic materials were studied by FT-IR using a Varian 4100 FT-IR Excalibur series apparatus (Variant Inc, CA, USA) in ATR mode (wave number $=4000-500 \mathrm{~cm}^{-1}, 64$ scan and $2 \mathrm{~cm}^{-1}$ resolution). The spectra were collected by placing a flat fragment of the ceramic disks on the diamond face of the ATR apparatus.

The weight changes during pyrolysis were followed by termogravimetrical analysis, TGA, using a Netzsch STA 409 analyzer (Netzsch Gmbh) operating under $\mathrm{Ar}, \mathrm{CO}_{2}$ flow $\left(50 \mathrm{~mL} \mathrm{~min}{ }^{-1}\right)$ up to $1200^{\circ} \mathrm{C}$ with a heating rate of $10^{\circ} \mathrm{C} \mathrm{min}^{-1}$. The polymeric films were first crashed into coarse powders using an agate mortar and then about $50 \mathrm{mg}$ were loaded into the alumina crucible of the TGA equipment. The TGA equipment was evacuated and then filled with the specific gas $\left(\mathrm{Ar}\right.$ or $\left.\mathrm{CO}_{2}\right)$ for three 
times before starting the experiments. For comparison purposes TGA of the starting polymeric films was also recorded in flowing air using the same experimental conditions as for the $\mathrm{Ar}$ and $\mathrm{CO}_{2}$ experiments.

Scanning electron microscopy, SEM, micrographs were obtained both on the surface of the ceramic disks in contact with the pyrolysis gas and on the fracture surface. A JEOL JSM-5500 SEM equipment (Jeol Corp) was employed and the samples were previously coated with a thin Pt-Pd metallic layer.

Energy-dispersive X-ray spectroscopy, EDXS, was employed to study the composition profile beneath the pyrolysis surface. For this purpose, a Jeol IT300 (with tungsten filament) SEM instrument (Jeol Corp.), equipped with the EDXS detector (XFlash $^{\circledR}$ SSD $30 \mathrm{~mm}^{2}$ ), was used and the data were analyzed with the Brucker software. The investigated samples were embedded in an epoxy resin and polished down to $1 \mu \mathrm{m}$ diamond paste to show their section. In order to have a better spatial resolution, the polished cross section was tilted of ca. $60^{\circ}$ with respect to direction normal to samples external surface. Before EDXS the samples were coated with a thin Au film.

Vickers hardness, HV, tests were performed on the pristine pyrolysis surface of the glass disks using a FM-310 microhardness tester (Future Tech). For each sample, that is, $\mathrm{SiOC}-\mathrm{Ar}, \mathrm{SiOC}-\mathrm{CO}_{2}, \mathrm{SiCN}-\mathrm{Ar}$ and $\mathrm{SiCN}-\mathrm{CO}_{2}, 5$ different disks were tested, on each disk the hardness was measures using five loads $(0.981,1.962,2.943,4.910,9.81 \mathrm{~N})$ and for each load the measurement was repeated 10 times. Accordingly, for each samples and indentation load, the HV was the average on 50 measurements. The indentation tests were performed with a loading time of 15 seconds and keeping the maximum load for 10 seconds.

Nanoindentation tests were used to examine the hardness and Young's modulus variation from the surface to the bulk of the samples. The tests were performed on the SiOC polished samples (prepared in the same fashion as for the EDXS analysis). Tests were performed using a iNano instrument (Nanomechanics, Inc) equipped with a Berkovich indenter and following NanoBlitz 3D Release method (which allows to map the property variation in the selected area). The $10 \times 10$ indentation matrices were defined in a region of $72 \times 72 \mu \mathrm{m}$, with $8 \mu \mathrm{m}$ spacing between each indentation in each direction. The indentation matrices were performed starting from the edge of the specimen in the thickness direction (corresponding to the pyrolysis surface of the disk), with a load of $45 \mathrm{mN}$. Three matrices were examined on each specimen. A Poisson's ratio of 0.13 was used for obtaining the elastic modulus. ${ }^{29}$

The elastic modulus of the samples was also measured by three-point bending experiments. In this case, rectangular specimens 4-4.5 mm wide, $15 \mathrm{~mm}$ long, and 0.2-0.25 mm thick where obtained from the pyrolyzed disks by polishing them with $\mathrm{SiC}$ paper (Figure S1).

Load displacement curves were obtained with an Instron 5969 testing machine (Instron) using $1 \mathrm{kN}$ load cell, threepoint configuration with $10 \mathrm{~mm}$ span length and displacement rate of $10 \mathrm{~mm} \mathrm{~min}^{-1}$. The compliance of the Instron equipment was assessed using thin $(150 \mu \mathrm{m})$ soda-lime glass samples with $E=72 \mathrm{GPa}$. The results suggested that, in the experimental conditions used for measuring the elastic modulus of the SiOC glasses, the maximum deformation of the measuring equipment was less than $1 \%$ and was therefore neglected in the elaboration of the data.

\section{3 | RESULTS}

The mass and length changes of the polymeric preceramic disks during pyrolysis were measured and the results are reported in Table 1 together with the bulk density values.

For both systems the ceramic yield in $\mathrm{CO}_{2}$ flow is extremely high, above $~ 90-95 \mathrm{wt} \%$, and approaches the highest ceramic yield ( $97 \mathrm{wt} \%$ ) reported for a PDC. ${ }^{36}$ Density values are in line with those reported for SiOC and SiCN PDCs. ${ }^{1}$ The pyrolythic transformation was further studied by TGA analysis (Figure 2). The TGA curves were also recorded in air for comparison. Figure 2 confirms that pyrolysis in $\mathrm{CO}_{2}$ leads to higher ceramic yields than pyrolysis in Ar atmosphere, as already observed on the disk samples (Table 1). The mass change obtained from the TGA curves at $1200^{\circ} \mathrm{C}$ in $\mathrm{Ar}$ is rather similar to the one measured on the disk samples. On the other hand, the ceramic yield obtained by TGA in $\mathrm{CO}_{2}$ does not exactly match with the disks one: the weight change measured on the disks was slightly negative $(\sim-5 \%$ and $\sim-10 \%$ for SiOC and SiCN, respectively), whereas the TGA shows a small increase ( $3 \%$ for $\mathrm{SiOC}$ and $\sim 1 \%$ for $\mathrm{SiCN})$. This discrepancy can be reasonably attributed to the slightly different thermal cycle used in the two experiments. In particular, TGA analysis was carried out in $\mathrm{CO}_{2}$ up to $1200^{\circ} \mathrm{C}$, whereas disk samples were treated in $\mathrm{CO}_{2}$ only up to $800^{\circ} \mathrm{C}$ (and then the atmosphere was switched to Ar). Moreover, the TGA samples were crashed into powders, thus exposing to the reactive atmosphere a larger surface area per unit of mass. It is therefore very reasonable to assume that the TGA conditions were more favorable for facilitating a good gas-solid contact than the ones obtained for the disks pyrolysis, thus leading to a more complete conversion of the $\mathrm{Si}-\mathrm{C}, \mathrm{Si}-\mathrm{N}$ bonds into $\mathrm{Si}-\mathrm{O}$. 
As oxidation of $\mathrm{Si}_{3} \mathrm{~N}_{4}$ and $\mathrm{SiC}$ is coupled with a weight gain, this can explain why the TGA analysis measured a higher ceramic yield.

Pyrolysis of the SPR-036 samples (SiOC) in Ar flow results into a typical decomposition curve ${ }^{37}$ showing good weight stability up to $\sim 400^{\circ} \mathrm{C}$ and then a major weight loss step ending at $\sim 800^{\circ} \mathrm{C}$ with a loss of $\sim 14 \mathrm{wt} \%$. When the $\mathrm{CO}_{2}$ flow is used, TGA shows a weight increase starting a $\sim 300^{\circ} \mathrm{C}$ with a maximum at $\sim 350^{\circ} \mathrm{C}$ and then a weight loss up to $\sim 600^{\circ} \mathrm{C}$. Above this temperature the mass of the sample is rather stable with a small weight increase/decrease centered at $\sim 800^{\circ} \mathrm{C}$. Interestingly, pyrolysis in air results into a TGA curve similar to the one in $\mathrm{CO}_{2}$ but shifted to lower temperature. The weight increase step starts at $\sim 200^{\circ} \mathrm{C}$ and reaches the maximum $\sim 300^{\circ} \mathrm{C}$. The weight loss step ends at $\sim 800^{\circ} \mathrm{C}$ and above that temperature the weight is stable.

Thermogravimetrical analysis of the Durazane-based precursor $(\mathrm{SiCN})$ shows similar results. TGA plot in Ar flow reveals that the decomposition starts at lower temperature, compared to the siloxane system, due to a lower cross-linking degree of this precursor. In this case, the first weight loss step between $200^{\circ} \mathrm{C}$ and $300^{\circ} \mathrm{C}$ is most probably due to the evaporation of low molecular weight fragments of the preceramic polymer. The weight loss continues up to $800^{\circ} \mathrm{C}$ when the mass of the samples become stable. TGA curve in $\mathrm{CO}_{2}$ flow starts with the same weight loss step observed in Ar atmosphere (confirming that it is related to an evaporation process) but then, around $350^{\circ} \mathrm{C}$, the mass increases and the mass gain persists up to $\sim 550^{\circ} \mathrm{C}$. In air atmosphere the shape of the TGA plot is similar but shifted to lower temperatures and the onset of the oxidation appears wellbefore the first weight loss step.

FT-IR spectra were recorded in ATR mode on the surface of the pyrolyzed disks exposed to the gas flow during pyrolysis (Figure S2). The penetration depth of the infrared

TABLE 1 Ceramic yield, shrinkage, and bulk density of the SiOC and SiCN glasses after pyrolysis at $1200^{\circ} \mathrm{C}$ according to the thermal cycle shown in Figure 1

\begin{tabular}{|c|c|c|c|c|c|c|}
\hline \multirow[t]{2}{*}{ Sample } & \multicolumn{2}{|c|}{ Ceramic Yield (wt\%) } & \multicolumn{2}{|c|}{ Shrinkage (\%) } & \multicolumn{2}{|c|}{ Density $\left(\mathrm{g} \mathrm{cm}^{-3}\right)$} \\
\hline & Ar & $\mathrm{CO}_{2}$ & Ar & $\mathrm{CO}_{2}$ & Ar & $\mathrm{CO}_{2}$ \\
\hline $\mathrm{SiOC}$ & $88.8 \pm 0.8$ & $95.4 \pm 1.4$ & $24.3 \pm 0.8$ & $19.9 \pm 1.8$ & $2.14 \pm 0.28$ & $2.14 \pm 0.02$ \\
\hline $\mathrm{SiCN}$ & $77.2 \pm 1.7$ & $89.5 \pm 3.1$ & $26.5 \pm 0.6$ & $22.4 \pm 1.9$ & $2.08 \pm 0.12$ & $2.03 \pm 0.08$ \\
\hline
\end{tabular}

FIGURE 2 TGA curves recorded on $\mathrm{SiOC}$ and $\mathrm{SiCN}$ preceramic samples under different atmospheres. Experimental conditions: $10^{\circ} \mathrm{C} \mathrm{min}^{-1}$, gas flow $50 \mathrm{~mL} \mathrm{~min}^{-1}$. In all the curves the weight increase observed between $\mathrm{RT}$ and $200^{\circ} \mathrm{C}$ is an instrumental artifact due to the buoyancy effect [Color figure can be viewed at wileyonlinelibrary.com]
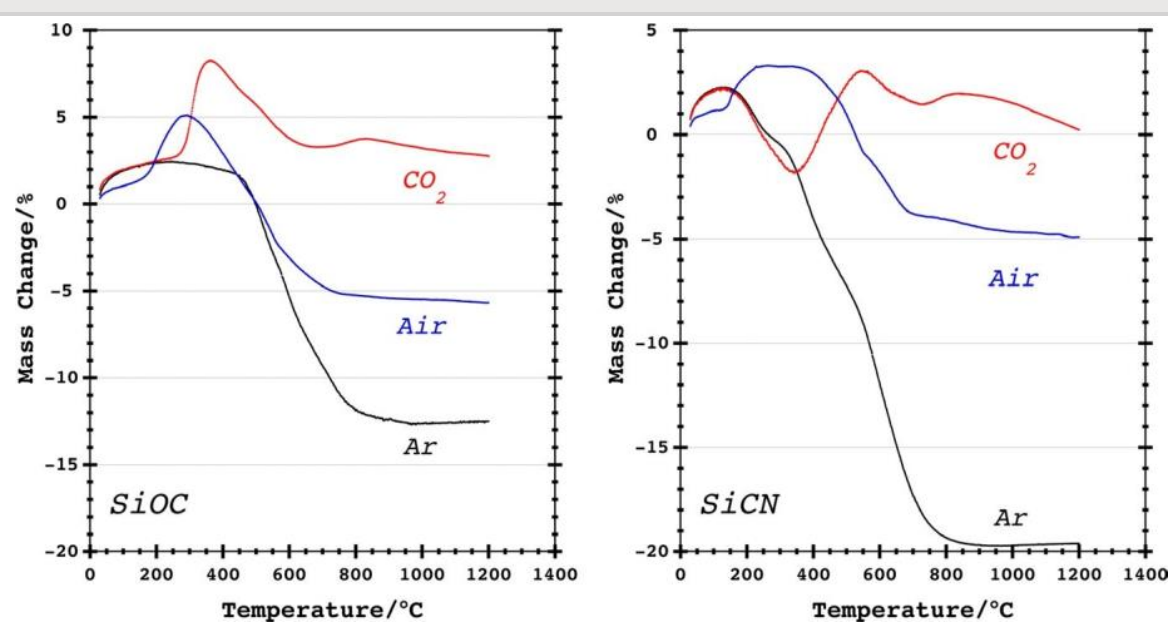

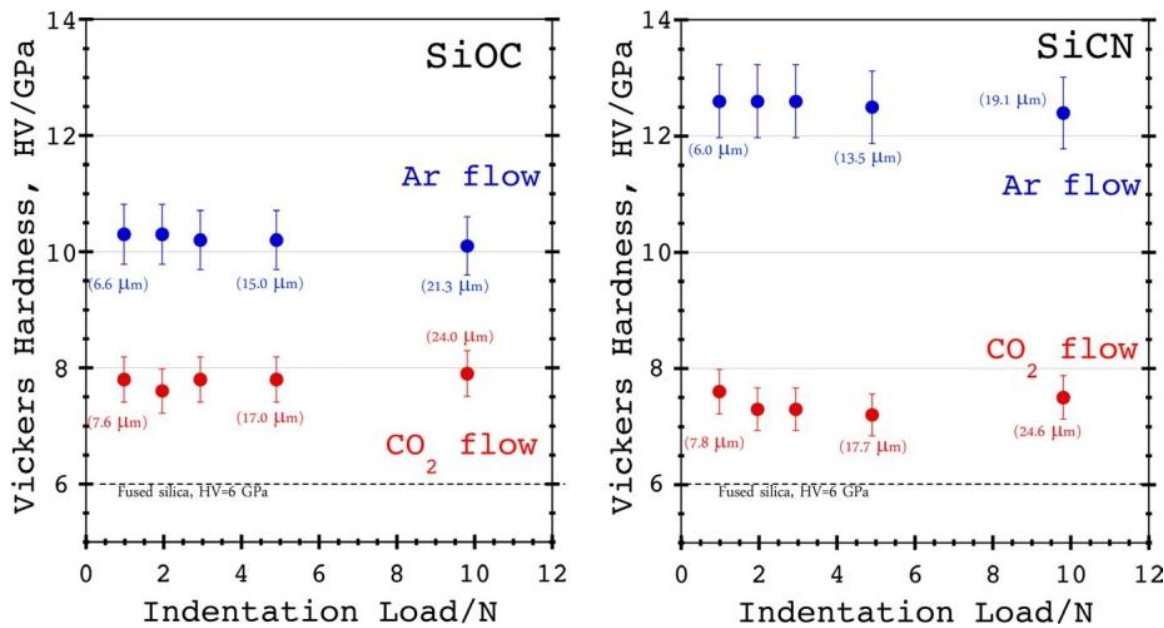

FIGURE 3 Vickers hardness, $\mathrm{HV}$, values measured for the $\mathrm{SiOC}$ and $\mathrm{SiCN}$ glasses pyrolyzed in $\mathrm{Ar}$ and $\mathrm{CO}_{2}$ atmosphere at $1200^{\circ} \mathrm{C}$ (according to the thermal cycle shown in Figure 1), as a function of the indentation load. The values are the average of 50 indentations. The bar at each point is the standard deviation. The values in brackets represent the penetration depth of the plastic zone beneath the indenter considered to be hemispherical with a radius equal to the half diagonal of the indentation impression [Color figure can be viewed at wileyonlinelibrary.com] light is of the order of few micrometers; therefore, ATR FT-IR samples only the surface properties. IR spectrum of SiCN pyrolyzed in Ar shows a broad absorption in the range 1100-800 $\mathrm{cm}^{-1}$ which probably encompasses the contribution of Si-C $\left(\sim 800 \mathrm{~cm}^{-1}\right), \mathrm{Si}-\mathrm{N}\left(\sim 960 \mathrm{~cm}^{-1}\right)$, and $\mathrm{Si}-\mathrm{O}\left(1000-1100 \mathrm{~cm}^{-1}\right.$ and $\left.780-800 \mathrm{~cm}^{-1}\right)$ bonds vibrations. ${ }^{38,39}$ On the other hand, the three IR spectra recorded on the SiOC system in $\mathrm{Ar}$ and $\mathrm{CO}_{2}$ and on the $\mathrm{SiCN}-\mathrm{CO}_{2}$ are very similar to each other. They show two peaks, the main one in the range $1100-1000 \mathrm{~cm}^{-1}$ and a second, smaller one, at $800-790 \mathrm{~cm}^{-1}$, both of them related to $\mathrm{Si}-$ O vibrations of the silica-based network.

The Vickers hardness values measured on the $\mathrm{SiOC}$ and $\mathrm{SiCN}$ glasses pyrolyzed at $1200^{\circ} \mathrm{C}$ in $\mathrm{Ar}$ and $\mathrm{CO}_{2}$ atmosphere are shown in Figure 3 and the values are also reported in Table S1.

For both systems and in both pyrolysis atmospheres the hardness does not change with the indentation load. HV of the SiOC and SiCN pyrolyzed in Ar atmosphere is $\sim 10.4$ and $\sim 12.6 \mathrm{GPa}$, respectively, in agreement with the literature. ${ }^{20,29,40}$ Pyrolysis in $\mathrm{CO}_{2}$ results into a strong decrease in the hardness which drops down to $\sim 7.8 \mathrm{GPa}$ for $\mathrm{SiOC}-\mathrm{CO}_{2}$ and to $\sim 7.4 \mathrm{GPa}$ for $\mathrm{SiCN}-$ $\mathrm{CO}_{2}$ with a decrease in $\sim 25 \%$ and $\sim 40 \%$, respectively. Vickers hardness of samples pyrolyzed in $\mathrm{CO}_{2}$ flow approaches the value reported in the literature $(6 \mathrm{GPa})$ for fused silica ${ }^{41}$ and also measured in this study on a commercial silica glass (HeraeusHSQ300, Kleinostheim). These results suggest that $\mathrm{CO}_{2}$ treatment produces SiOC and SiCN materials in which the disordered network (embedding the $\mathrm{C}_{\text {free }}$ phase) is closer to amorphous silica than to amorphous silicon oxycarbide or silicon carbonitrides, respectively. Such result was expected for the SPR-036 siloxane precursor but it is quite surprising for the Durazane-based system. Indeed, for the polysilazane precursor the $\mathrm{CO}_{2}$ reactive atmosphere must have oxidized not only the $\mathrm{Si}-\mathrm{C}$ bonds but also the $\mathrm{Si}-\mathrm{N}$ bonds present in the polymeric backbone. The formation of a silica-like structure at the surface of the $\mathrm{SiOC}$ and SiCN samples pyrolyzed in $\mathrm{CO}_{2}$ flow is also confirmed by analyzing the indentation fracture patterns (Figure 4). They clearly show that Vickers indentations in $\mathrm{SiOC}-\mathrm{CO}_{2}$ and $\mathrm{SiCN}-\mathrm{CO}_{2}$ result in the formation of Hertzian cone cracks, which are typical of anomalous glasses such as fused silica. ${ }^{42-44}$ The indentations performed on the SiOC-Ar and SiCN-Ar do not show the formation of any radial cracks up to $9.8 \mathrm{~N}$ load suggesting a high resistance toward crack initiation, as already reported for SiOC PDCs. ${ }^{45}$

As said, $\mathrm{HV}$ of the samples pyrolyzed in $\mathrm{CO}_{2}$ is close to the one measured on pure $\mathrm{SiO}_{2}$ glass; however, the measured values, for both samples treated in $\mathrm{CO}_{2}$, are still above $6 \mathrm{GPa}$. We could explain this result either assuming that not all the Si-C and $\mathrm{Si}-\mathrm{N}$ bonds were transformed into $\mathrm{Si}-\mathrm{O}$ bonds or that the presence of free $\mathrm{C}$ nanodomains in the silica network by itself can increase the hardness. The latter hypothesis seems less likely as our previous work showed that $H$ and $E$ decreases with increasing the volume fraction of free $\mathrm{C}$ in silicon oxycarbide glasses. ${ }^{29}$ 
There is another interesting result that emerges from the hardness study: $\mathrm{HV}$ is independent from the indentation load which implies that the hardness is independent from the indentation depth for the investigated loads. The values in brackets in Figure 3 report the size of the plastic zone beneath the indenter. The plastic zone is considered to be hemispherical with a radius equal to the half diagonal of the indentation impression. Accordingly, we can estimate that the depth of the plastic zone reaches thicknesses as high as $25 \mu \mathrm{m}$ for a load of $9.81 \mathrm{~N}$ and being the hardness constant in all this range, the compositional and structural modification induced by the reactive $\mathrm{CO}_{2}$ atmosphere have at least reached this depth. This is not a trivial result since it is quite difficult to predict at which maximum depth the $\mathrm{CO}_{2}$ gas could diffuse and react upon PDCs pyrolysis.

To get more insights into the evolution of the composition and of the mechanical properties beneath the surface of the samples, EDXS analysis, and nanoindentation tests were performed on the SiOC samples. Corresponding investigation on SiCN system were not performed at this time since a detail study for the Durazane-derived ceramics will be the subject of the next
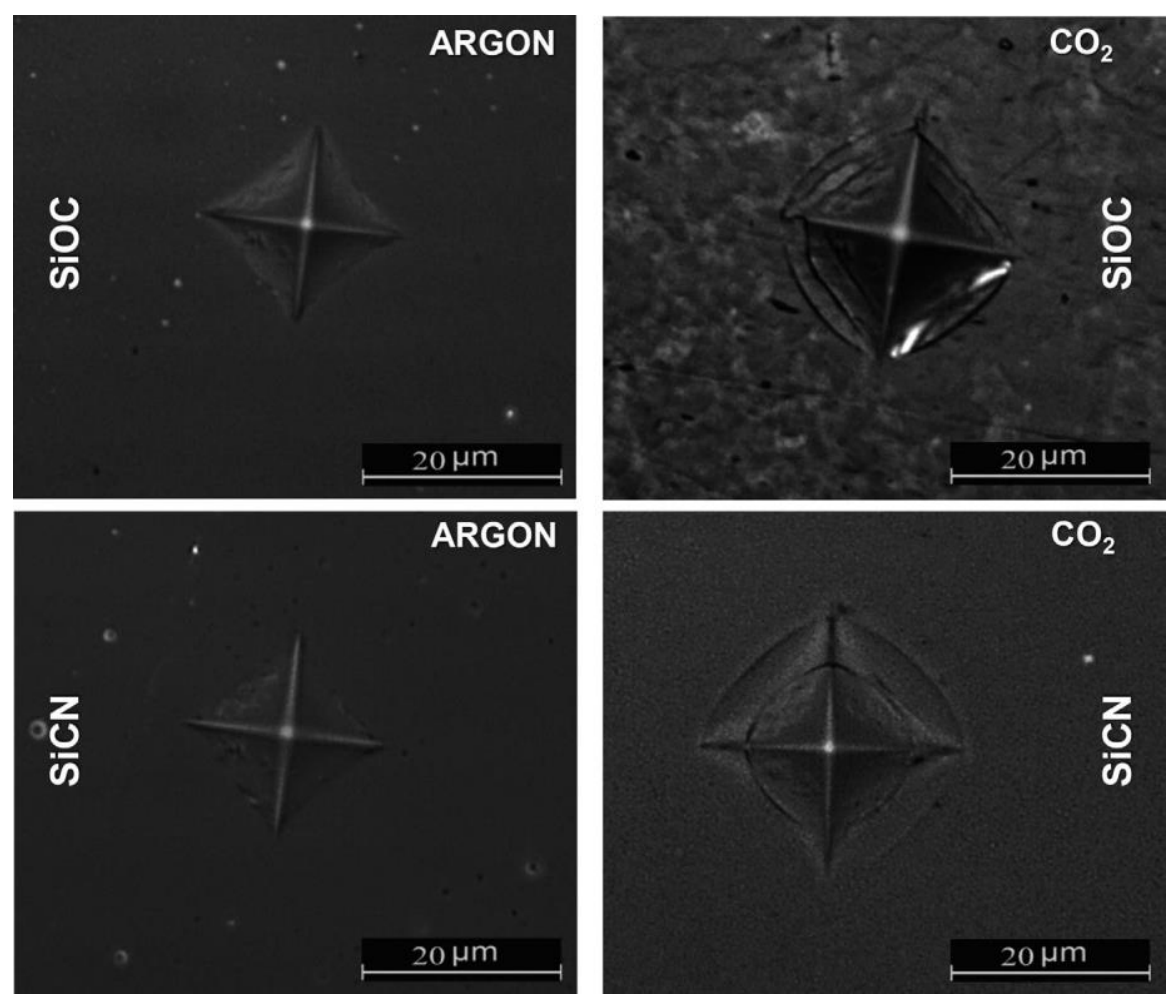

work.

Figure 5 shows $\mathrm{Si}, \mathrm{C}$, and $\mathrm{O}$ profile measured for the $\mathrm{Ar}$ and $\mathrm{CO}_{2}$ treated SiOC samples. Since EDXS is not strictly quantitative (especially when dealing with light elements as C), we prefer to report only how the EDXS counts for each element changes as moving from the surface to the core. Such measurement, albeit not giving the exact composition of the material, allows to follow-up the qualitative composition evolution along the profile. In other words, Figure 5 allows only to identify trends in the elemental composition moving from the surface to the core, but the measure remains not quantitative.

$\mathrm{SiOC}-\mathrm{Ar}$ shows flat profiles for all the three elements up to a depth of $\sim 15$ $\mu \mathrm{m}$. On the other hand, the $\mathrm{SiOC}-\mathrm{CO}_{2}$ clearly shows an evolution of the $\mathrm{O}$ and $\mathrm{C}$ profiles, in particular $\mathrm{O}$ counts decrease for the first 25-30 $\mu \mathrm{m}$ and $\mathrm{C}$ counts correspondingly increases. Si concentration is constant through the studied depth length. These results indicate that: (a) carbon dioxide is a source of oxygen and, at the same time, removes $\mathrm{C}$ from the 
FIGURE 4 Vickers indentations

obtained on the $\mathrm{SiOC}$ and $\mathrm{SiCN}$ glasses after pyrolysis at $1200^{\circ} \mathrm{C}$ according to the thermal cycle shown in Figure 1 . All the indentations were obtained with a load of $2.94 \mathrm{~N}$. Typical Hertzian cracks are clearly visible fir the $\mathrm{CO}_{2}$ treated samples

FIGURE 5 EDXS counts of $\mathrm{Si}, \mathrm{C}$, and $\mathrm{O}$ elements collected on the $\mathrm{SiOC}-\mathrm{Ar}$ and $\mathrm{SiOC}-\mathrm{CO}_{2}$ samples as a function of the distance from the surface. Note that the analysis is not quantitative but provides a qualitative information on the elemental composition evolution of the samples beneath their external surface [Color figure can be viewed at wileyonlinelibrary.com]

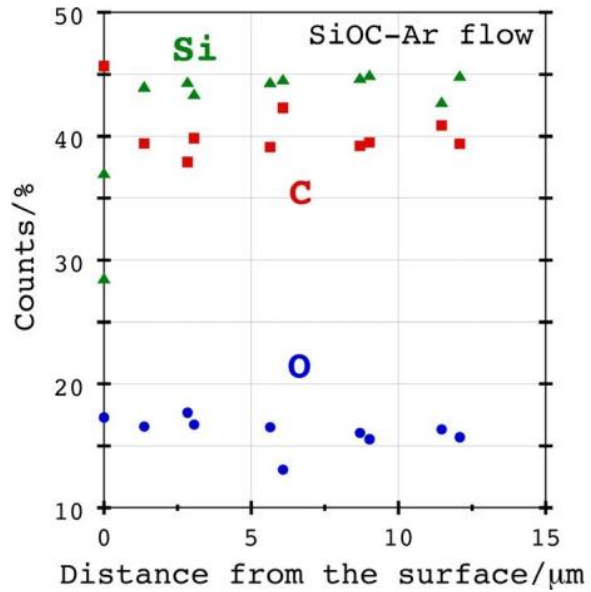

Distance from the surface/ $/ \mu \mathrm{m}$

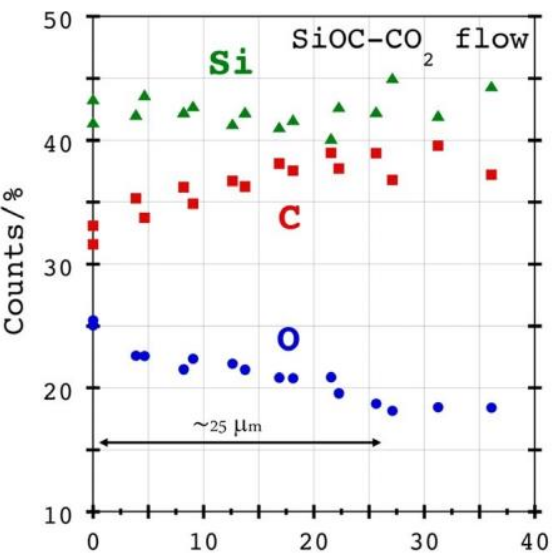

Distance from the surface/um MODULUS
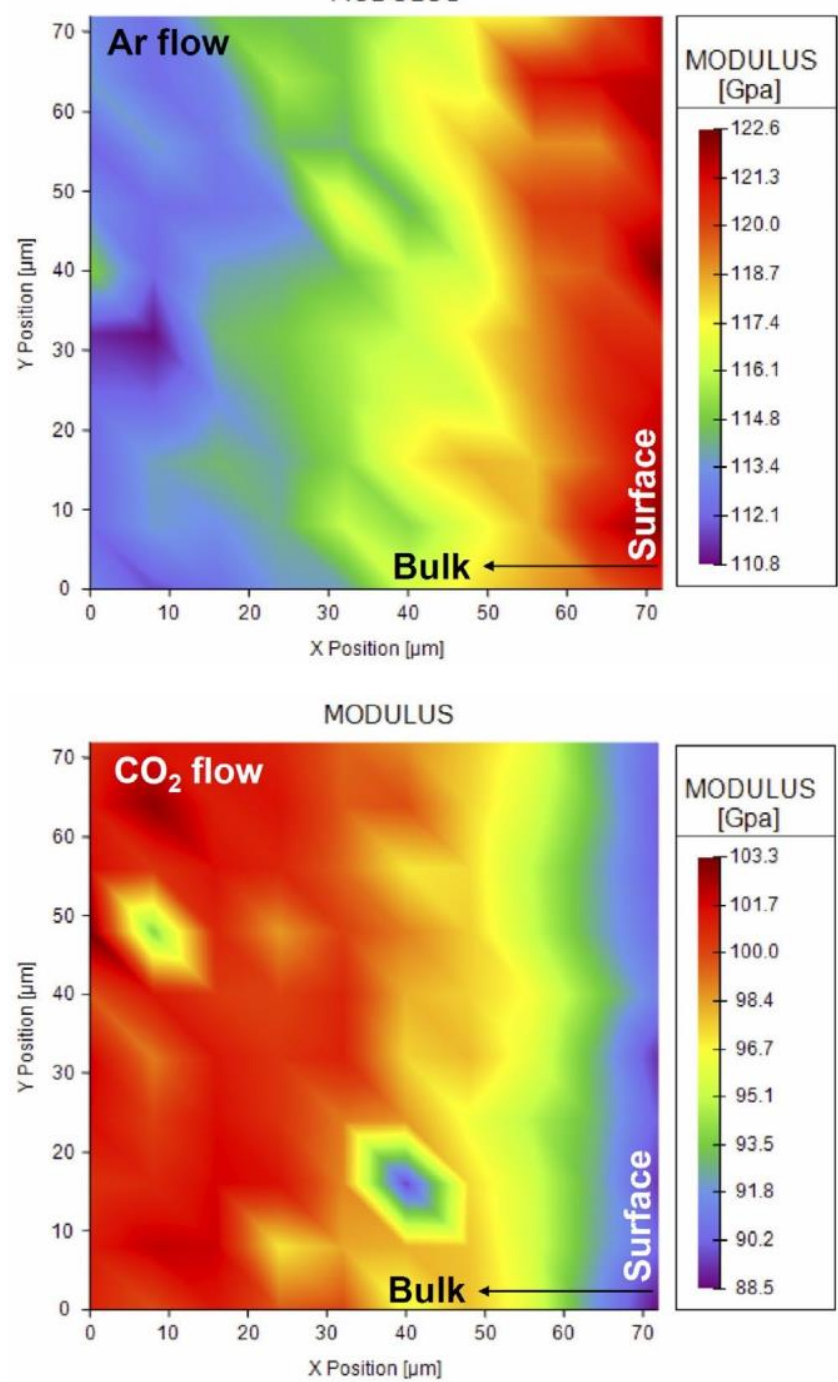

FIGURE 6 Nanoindentation gradient maps, hardness and elastic modulus, of SiOC samples pyrolyzed at $1200^{\circ} \mathrm{C}[\mathrm{Color}$ figure can be viewed at wileyonlinelibrary.com] 
surface of the sample and (b) the penetration of $\mathrm{CO}_{2}$ into the evolution beneath the surface (see the nanoindentation matritransforming siloxane reaches, at least, $25 \mu \mathrm{m}$. ces in Figure S3). The average values of $H$ and $E$ are shown

Nanoindentation maps for the SiOC sample are reported in Figure 7 as a function of the distance from the surface (raw in Figure 6 showing the hardness and elastic modulus data available in Table S2).
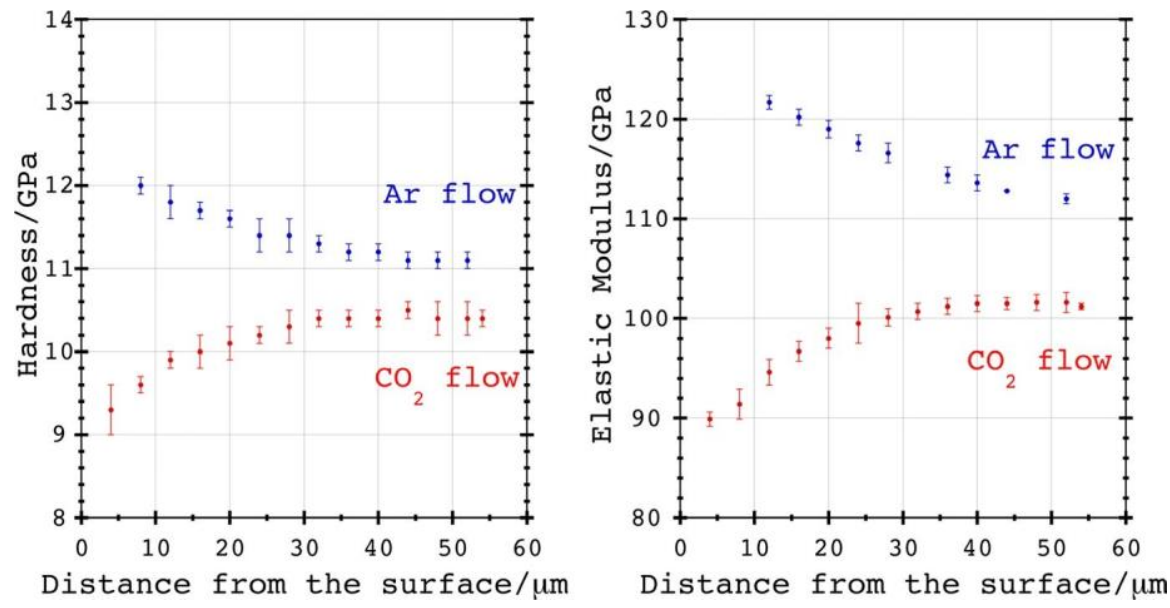

FIGURE 7 Nanoindentation hardness and elastic modulus profile curves along the thickness of SiOC samples pyrolyzed at $1200^{\circ} \mathrm{C}$ [Color figure can be viewed at wileyonlinelibrary.com]

Figures 6 and 7 clearly show that hardness and elastic modulus values of SiOC-Ar are higher near the surface of the sample and decrease toward the bulk. On the contrary, the $H$ and $E$ for SiOC$\mathrm{CO}_{2}$ samples are lower close to the edge. The $H$ and $E$ profiles in Figure 7 reveal that the properties gradient reaches a depth of $\sim 30 \mu \mathrm{m}$ in good agreement with the EDXS results. It is worth of note that the measured gradient of the nanohardness values was different when compared to Vickers hardness data which suggested independence of the HV from the indentation load, that is, from the depth of penetration of the plastic deformation zone beneath the indenter (approximately $25 \mu \mathrm{m}$ ). However, nanoindentation samples a much smaller volume (less than a few $\mu \mathrm{m}^{3}$ ) compared to the Vickers microindentation which involves a volume ranging from hundred to several thousand of $\mu \mathrm{m}^{3}$. Using, a simple geometrical consideration we can calculate that $70 \%$ of the volume of the plastic deformation beneath the indenter is located in the first half of the maximum penetration depth. It means that, even if the maximum penetration depth in the Vickers tests is around $25 \mu \mathrm{m}, 70 \%$ of the plastic deformation occurs in the first $12.5 \mu \mathrm{m}$ suggesting that the resulting hardness is more related to the properties of the first layers rather than being an average value over the first 25-30 $\mu \mathrm{m}$.

The elastic modulus of the $\mathrm{SiOC}$ and $\mathrm{SiCN}$ glasses after pyrolysis in $\mathrm{Ar}$ and $\mathrm{CO}_{2}$ atmosphere was also measured by threepoint bending test (Figure S1) and the results are reported in Table 2.

The rather low values of bending strength is related to the high defective state of the edges of the samples obtained from the pyrolyzed disks by polishing with $\mathrm{SiC}$ paper, whereas the large variation in the elastic modulus is most probably due to the not perfect geometrical feature of the investigated samples in terms of planarity and parallelism of the surfaces. Nevertheless, the elastic modulus values are in line with the previous results revealing a decrease in elastic modulus from the Ar-treated samples to the $\mathrm{CO}_{2}$-treated ones. Interestingly even the lower $E$ values, that is, those measured on the $\mathrm{CO}_{2}$ treated samples are above the value reported for fused silica

TABLE 2 Elastic modulus and bending strength measured by three-point bending tests on SiOC and SiCN samples

\begin{tabular}{|lll|}
\hline Sample & $\begin{array}{l}\text { Elastic modulus } \\
\text { (GPa) }\end{array}$ & $\begin{array}{l}\text { Bending } \\
\text { strength }(\mathbf{M P a})\end{array}$ \\
\hline $\mathrm{SiOC}-\mathrm{Ar}$ & $168 \pm 10$ & $70 \pm 18$ \\
\hline $\mathrm{SiOC}-\mathrm{CO}_{2}$ & $102 \pm 12$ & $84 \pm 10$ \\
\hline $\mathrm{SiCN}-\mathrm{Ar}$ & $189 \pm 16$ & $70 \pm 15$ \\
\hline $\mathrm{SiCN}-\mathrm{CO}_{2}$ & $127 \pm 12$ & $102 \pm 15$ \\
\hline
\end{tabular}

$\left(E_{\mathrm{SiO} 2}=70 \mathrm{GPa}\right),{ }^{46}$ pointing out only a partial conversion of the $\mathrm{Si}-\mathrm{C}$ and $\mathrm{SiN}$ bonds into $\mathrm{Si}-\mathrm{O}$ ones.

\section{DISCUSSION}

Data reported in Table 1 show that pyrolysis in reactive $\mathrm{CO}_{2}$ leads, for both $\mathrm{SiOC}$ and $\mathrm{SiCN}$, to higher ceramic yields and lower linear shrinkages, compared to inert atmosphere. These results are in agreement with those reported by Narisawa et al obtained for a methyl-silsequioxane preceramic polymer. ${ }^{32}$ On the other hand, there are no data available in the literature for 
polysilazanes pyrolyzed in $\mathrm{CO}_{2}$ flow and, therefore, these are the first results suggesting that polysilazanes seem to behave, during pyrolysis, similarly to the siloxane precursors.

TGA analysis performed on SPR-036-based samples (Figure 2) reveal that, compared to the inert gas (Ar), the reactivity of $\mathrm{CO}_{2}$ starts at rather low temperature $\left(300^{\circ} \mathrm{C}\right)$ resulting into a weight increase which seems to be related to an oxidation of the precursor. Indeed, the pyrolysis in air, which is a stronger oxidizing agent compared to $\mathrm{CO}_{2}$, leads to similar results, with a TGA curve just shifted to lower temperature. The chemical reaction involved in the weight increase step recorded for the SPR-036 samples between 300 and $350^{\circ} \mathrm{C}$ is not known in detail at this moment (a more careful study of the pyrolysis process of these precursors in different atmospheres using complementary spectroscopic techniques will be reported in the near future). However, based on the data published by Belot et a ${ }^{47}$ and by some of us ${ }^{48}$ we can postulate that it could be related to the transformation of the $\mathrm{Si}-\mathrm{H}$ and/or $\mathrm{Si}-\mathrm{CH}_{3}$ moieties present in the precursor with the formation of $\mathrm{Si}-\mathrm{O}$ bonds and a corresponding weight gain. Thus, TGA reveals that at least a very relevant part of the oxidation reaction takes place well-before the complete ceramization of the network, and could substantially eliminate the groups that, upon pyrolysis, leads to the formation of the $\mathrm{Si}-\mathrm{C}$ bonds (ie, $\mathrm{Si}-\mathrm{H}$ and $\mathrm{Si}-\mathrm{CH}_{3}$ convert into $\mathrm{Si}-\mathrm{C}$ carbidic bonds at high temperature releasing low molecular weight hydrocarbons and molecular hydrogen). Thus, the reaction between the preceramic resin and $\mathrm{CO}_{2}$ leads to a substantial reduction in the $\mathrm{Si}-\mathrm{C}$ bonds in the $\mathrm{SiOC}$ matrix, whereas it does not reduce the free carbon phase. Further investigations would be needed to unravel the reactions between the preceramic resins and $\mathrm{CO}_{2}$ and could be part of a new work in the next future.

Thermogravimetrical analysis of the Durazane-based precursor shows similar results. The weight increase step, probably related to the transformation of $\mathrm{Si}-\mathrm{H}, \mathrm{Si}-\mathrm{CH}_{3}$, and eventually $\mathrm{Si}-\mathrm{N}$ bonds starts around $350^{\circ} \mathrm{C}$ for the $\mathrm{CO}_{2}$ gas and is shifted to lower temperature for pyrolysis in air atmosphere. ${ }^{49}$

It is worth noting that, for both precursors, the ceramic yield in $\mathrm{CO}_{2}$ is higher than in air. We can tentatively explain this result by assuming that, air being a stronger oxidizing agent than $\mathrm{CO}_{2}$, the free $\mathrm{C}$ phase which forms during pyrolysis can be oxidized more easily by $\mathrm{O}_{2}$ than $\mathrm{CO}_{2}$. Since oxidation of $\mathrm{C}_{\text {free }}$ leads to a net mass loss this could explain the observed results.

FT-IR results (Figure S2) show the main IR absorption for the $\mathrm{SiOC}-\mathrm{Ar}, \mathrm{SiOC}-\mathrm{CO}_{2}$, and $\mathrm{SiCN}-\mathrm{CO}_{2}$ at 1028,1046 , and $1036 \mathrm{~cm}^{-1}$, respectively. They indicate that the samples treated in $\mathrm{CO}_{2}$ show a blue shift of $\sim 8-18 \mathrm{~cm}^{-1}$ compared to the SiOC pyrolyzed in Ar. A similar blue shift value of $\sim 10-20 \mathrm{~cm}^{-1}$ was observed between $\mathrm{SiOC}$ pyrolyzed in $\mathrm{Ar}$ and $\mathrm{CO}_{2}$ and it was assumed as an indication that carbon dioxide converts the $\mathrm{Si}-\mathrm{C}$ bonds into $\mathrm{Si}-\mathrm{O}$ bonds leading to the formation of a $\mathrm{SiO}_{2} / \mathrm{C}_{\text {free }}$ silicon oxycarbide glass. ${ }^{32,33}$ Accordingly, the present results suggest that, for both systems, pyrolysis in $\mathrm{CO}_{2}$ leads to the formation, at the surface of the samples, of $\mathrm{SiO}_{2} / \mathrm{C}_{\text {free }}$ ceramic independently from the starting preceramic polymer.

Pyrolysis of siloxane preceramic polymers in reactive $\mathrm{CO}_{2}$ atmosphere was reported in the literature only in two studies. Narisawa group ${ }^{32}$ suggested, based on FT-IR, chemical analysis, and density data, the formation of a $\mathrm{SiO}_{2} / \mathrm{C}_{\text {free }} \mathrm{SiOC}$ which was confirmed by some of us with a ${ }^{29} \mathrm{Si}$ MAS NMR investigation study, performed on a siloxane aerogel. ${ }^{33}$ The precise reaction path occurring during $\mathrm{CO}_{2}$ pyrolysis is not known yet. It is conceivable to assume that, being a reaction between a gas and a solid phase, it could occur preferentially at the surface of the sample and that a gradient of composition/structure could exist in the sample. For this reason, in the present investigation, we choose to measure the Vickers microhardness and to collect FT-IR spectra in ATR mode to reveal the surface properties of the samples. The results obtained both on SiOC and SiCN (see Figures 3-4 and Figure S2) indicate that shifting the pyrolysis atmosphere from inert (Ar) to reactive $\left(\mathrm{CO}_{2}\right)$ leads to: (a) a surface bonding state which is close to that of silica, (b) HV approaches that of fused silica, although the hardness values are slightly higher $\left(\mathrm{HV}_{\mathrm{SiCN}-\mathrm{CO} 2} \sim 7.4, \mathrm{HV}_{\mathrm{SiOC}-\mathrm{CO} 2} \sim 7.8 \mathrm{GPa}\right.$ vs $\left.\mathrm{HV}_{\mathrm{SiO} 2}=6 \mathrm{GPa}\right)$, and (c) the indentation fracture pattern of the SiOC and $\mathrm{SiCN}$ samples pyrolyzed in $\mathrm{CO}_{2}$ flow are characterized by Hertzian cone cracks typical of anomalous glasses such as fused silica. The presence of a compositional and structural gradient beneath the samples surface cannot be proposed analyzing the evolution of $\mathrm{HV}$ with the indentation loads. Indeed, the flat $\mathrm{HV}$ vs indentation load profile shown in Figure 2 would suggest a homogeneous composition and structure up to $\sim 25 \mu \mathrm{m}$ beneath the surface. At first glance this could seem a rather high penetration depth for the diffusing $\mathrm{CO}_{2}$ gas, however, the TGA analysis (Figure 1) helps us in rationalize this result. The weight gain step, which is an indication of the $\mathrm{CO}_{2}$ reactivity toward the preceramic polymers, starts, for both systems, at quite low temperature (around $300^{\circ} \mathrm{C}$ ), that is, when the material is just beginning the organic-to-inorganic transformation and well before the formation of a tight inorganic network which could slow down the diffusion of $\mathrm{CO}_{2}$. Moreover, it is well-known that during pyrolysis the preceramic polymer develops a transient porosity in the range $500^{\circ} \mathrm{C}-900^{\circ} \mathrm{C}$, which could also contribute to the $\mathrm{CO}_{2}$ diffusion toward the bulk of the transforming disks. ${ }^{44,50}$ An additional indication that the effect of the $\mathrm{CO}_{2}$ treatment is not limited to the region near the surface comes from the results of the three-point bending tests (Figure S1 and Table 2). We choose, for these experiments, the thinnest samples of our study with a thickness of approximately $150200 \mu \mathrm{m}$. The reason for 
this choice was to increase, as much as possible, the relative content of the surface modified structure versus the potentially unmodified bulk of the sample. The results (Table 2) revealed that the thickness of the surface modified region is high enough to have a macroscopic impact on the elastic modulus of the samples and the variation follows the expected trend with a decrease in elastic modulus in the $\mathrm{CO}_{2}$-treated samples. The $E$ values for the SiOC-Ar appears slightly higher compared to known literature values, whereas those for $\mathrm{SiCN}-\mathrm{Ar}$ are in excellent agreement. ${ }^{28,31,51}$

Nanoindentation and EDXS studies performed on the sectioned pyrolyzed SiOC disks allowed to investigate the mechanical properties and elemental composition gradients. EDXS results (Figure 4) clearly show that the chemical composition for the $\mathrm{SiOC}-\mathrm{Ar}$ sample is homogeneous in the depth beneath the surface, whereas for the $\mathrm{SiOC}-\mathrm{CO}_{2}$ a gradient for the $\mathrm{O}$ and $\mathrm{C}$ content exists. In particular, $\mathrm{O}$ content is higher at the surface and decreases toward the bulk, whereas the opposite is observed for the $\mathrm{C}$ content. Interestingly, the extension of the gradient is $\sim 25 \mu \mathrm{m}$ and then the $\mathrm{O}$ and $\mathrm{C}$ counts flatten to a value that is slightly lower than that recorded for the Ar-pyrolyzed samples. It seems to suggests that, even in the bulk of the disk sample, in the region where the concentration of the elements is constant, the amount of oxygen is higher and the carbon is lower compared to the Ar-treated disk.

Analysis of the $H$ and $E$ profiles reported in Figure 7 reveal the presence of mechanical properties gradient. In the Ar-treated samples, $H$ and $E$ are higher at the surface when compared to the bulk. Since the EDXS show that no composition gradient exists, then this evidence can be explained assuming that the surface is more "transformed" into the final ceramic compared to the bulk of the samples. It is known that PDCs continue to densify even above $900^{\circ} \mathrm{C}$ (ie, above the temperature at which the samples substantially stop losing weight in the TGA trace) due to the release of molecular $\mathrm{H}_{2} .{ }^{52}$ As hydrogen in the amorphous PDCs network acts as a "chain breaker," its release leads to a more interconnected structure thus increasing $E$ and $H$ (the release of hydrogen is accompanied by formation of $\mathrm{Si}-\mathrm{C}, \mathrm{Si}-\mathrm{O}$, and $\mathrm{Si}-\mathrm{N}$ bonds). But on the other hand, since $\mathrm{H}_{2}$ has to diffuse out of the sample this could lead to a properties gradient, the regions closer to the outer surface containing less hydrogen compared to the inner parts. ${ }^{53}$

EDXS profiles of the $\mathrm{SiOC}-\mathrm{CO}_{2}$ sample show that the surface is oxygen-rich and carbon-deficient compared to the bulk. These results agree with the $H$ and $E$ profiles of the same samples showing that the hardness and elastic modulus are lower at the surface. Moreover, the thickness of the $H$ and $E$ gradients agree well with those observed by EDXS, that is, $\sim 30 \mu \mathrm{m}$. The hardness measured by nanoindentation is slightly larger than the one measured by Vicker's microhardness experiments. This can be attributed to various factors including scaling effects and also to increased cracking and chipping at higher loads. ${ }^{54}$

Finally, it is worth noting that $H$ and $E$ values measured at the core of the $\mathrm{CO}_{2}$-treated samples are always smaller than the corresponding values of the Ar pyrolyzed samples (the difference is about 10\%). This result suggests that the effect of $\mathrm{CO}_{2}$ atmosphere was able to reach the core (at least a depth $\geq 30 \mu \mathrm{m}$ ) of the samples. This result could be rationalized thinking that, when the transient porosity is open the $\mathrm{CO}_{2}$ can easily diffuse towards the centre of the specimen and then, after the porosity closes-up, still $\mathrm{CO}_{2}$ could react with the part of the sample closer to the surface finally setting the concentration (and properties) profiles that we demonstrated. This small but significant mechanical properties difference $(\sim 10 \%)$ in the core of SiOC samples pyrolyzed in $\mathrm{Ar}$ and $\mathrm{CO}_{2}$ appears in agreement with the EDXS results which pointed out that the oxygen load in the $\mathrm{CO}_{2}$-treated sample is slightly larger even in the bulk of the material.

\section{CONCLUSION}

This study reports the hardness and elastic modulus of thin, dense, polymer-derived $\mathrm{SiOC}$ and $\mathrm{SiCN}$ ceramics pyrolyzed in inert (Ar) and reactive $\left(\mathrm{CO}_{2}\right)$ atmosphere. Vickers hardness, $\mathrm{HV}$, was measured on the as-pyrolyzed surface of the samples, whereas the elastic modulus was estimated by threepoint bending tests. The elemental composition, hardness, and elastic modulus evolution beneath the surface was also investigated for the silicon oxycarbide system via EDXS and nanoindentation. The main results can be summarized as follows:

1. For both compositions, changing the pyrolysis atmosphere from $\mathrm{Ar}$ to $\mathrm{CO}_{2}$ leads to a strong drop of $\mathrm{HV}$, from $\sim 10.4$ to 7.8 $\mathrm{GPa}$ for $\mathrm{SiOC}$ and from $\sim 12.6$ to $\sim 7.4 \mathrm{GPa}$ for $\mathrm{SiCN}$. Moreover, the indentation fracture pattern for the $\mathrm{CO}_{2}$-treated samples shows Hertzian cone cracks. At the same time FT-IR spectra after pyrolysis in $\mathrm{CO}_{2}$ resemble that of fused silica. Taken all together, these evidences suggest that pyrolysis in $\mathrm{CO}_{2}$ flow promotes a consumption of $\mathrm{Si}-\mathrm{C}$ and $\mathrm{Si}-\mathrm{N}$ bonds with the formation of an amorphous network (embedding the free carbon phase) close to that of fused silica. 
2. For both compositions, the Young's modulus measured by three-point bending is lower for the $\mathrm{CO}_{2}$ treated samples compared to the Ar-treated ones. This result indicates that the effect of the reactive $\mathrm{CO}_{2}$ pyrolysis process is not limited to the vicinity of the surface as it could have been imagined.

3. EDXS and nanoindentation profiles showed that the modification of the elemental composition and of the $H$ and $E$ induced by the $\mathrm{CO}_{2}$ extends beneath the surface of the samples for $25-30 \mu \mathrm{m}$.

\section{ACKNOWLEDGMENTS}

The authors warmly acknowledge Prof. Masaki Narisawa for the helpful discussion. M. Biesuz and G.D. Sorarù kindly acknowledge the support from the Italian Ministry of University and Research (MIUR) within the programs PRIN2017 2017PMR932 "Nanostructured Porous Ceramics for Environmental and Energy Applications." L.K is supported by "Fondazione CARITRO: Laser surface microtexturing for tuning friction."

\section{ORCID}

Gian Domenico Sorarù (D) https://orcid.

org/0000-0002-0453-3379

Mattia Biesuz (D) https://orcid.org/0000-0002-4338-4177 REFERENCES

1. Colombo P, Mera G, Riedel R, Sorarù GD. Polymer-derived ceramics: 40 years of research and innovation in advanced ceramics. J Am Ceram Soc. 2010;93:1805-37. https://doi.org/10.1002/97835 $27631971 . c h 07$

2. Riedel R, Mera G, Hauser R, Klonczynski A. Silicon-based polymer-derived ceramics:synthesis, properties and applications-a review. J Ceram Soc Japan. 2006;444:33-8.

3. Stabler C, Roth F, Narisawa M, et al. High-temperature creep behavior of a SiOC glass ceramic free of segregated carbon. J Eur Ceram Soc. 2016;36(15):3747-53. https://doi.org/10.1016/j.jeurc erams oc.2016.04.015

4. Yajima S, Hayashi J, Omori M. Continuous silicon carbide fiber of high tensile strenght. Chem Lett. 1975;931-4.

5. Zhang L, Wang Y, Wei Y, et al. A silicon carbonitride ceramic with anomalously high piezoresistivity. J Am Ceram Soc. 2008;91(4):1346-9.

6. Ryu H-Y, Wang Q, Raj R. Ultrahigh-temperature semiconductors made from polymer-derived ceramics. J Am Ceram Soc. 2010;93:1668- 76. https://doi.org/10.1111/j.1551-2916.2010.03623.x

7. Karakuscu A, Guider R, Pavesi L, Sorarù GD. White luminescence from sol-gel-derived SiOC thin films. J Am Ceram Soc. 2009;92(12):296974. https://doi.org/10.1111/j.1551-2916.2009.03343.x

8. Dalcanale F, Grossenbacher J, Blugan G, et al. Influence of carbon enrichment on electrical conductivity and processing of polycarbosilane derived ceramic for MEMS applications. J Eur Ceram Soc. 2014;34:3559-70.

9. Gonzalo-Juan I, Detsch R, Mathur S, Ionescu E, Boccaccini AR, Riedel R. Silicon oxycarbide-based bioactive glasses. Materials. 2016;9(12): Article Number: 959.

10. Ishikawa T, Kohtoku Y, Kumagawa K, Yamamura T, Nagasawa T. High-strength alkali-resistant sintered SiC fibre stable to $2,200{ }^{\circ} \mathrm{C}$. Nature. 1998;20:773-5.

11. Konegger T, Williams LF, Bordia RK. Planar, polysilazane-derived porous ceramic supports for membrane and catalysis applications. J Am Ceram Soc. 2015;98(10):3047-53. https://doi.org/10.1111/jace.13758

12. Vakifahmetoglu C, Zeydanli D, Colombo P. Porous polymer derived ceramics. Mater Sci Eng Reports. 2016;106:1-30. https://doi. org/10.1016/j.mser.2016.05.001

13. Jana $\mathrm{P}$, Zera E, Sorarù GD. Processing of preceramic polymer to low density silicon carbide foam. Mater Des. 2017;116:278-86. https://doi.org/10.1016/j.matdes.2016.12.010

14. Sorarù GD, Dalcanale F, Campostrini R, et al. Novel polysiloxane and polycarbosilane aerogels via hydrosilylation of preceramic polymers. J Mater Chem. 2012;22(16):7676-80. https://doi. org/10.1039/c2jm0 0020b

15. Eckel ZC, Zhou C, Martin JH, Jacobsen AJ, Carter WB, Schaedler TA. Additive manufacturing of polymer-derived ceramics. Science. 2016;351(6268):58-62.

16. Kulkarni A, Sorarù GD, Pearce JM. Polymer-derived SiOC replica of material extrusion-based 3-D printed plastics. Addit Manuf. 2020;32:100988. https://doi.org/10.1016/j.addma.2019.100988

17. Liew L, Zhang W, An L, et al. Ceramic MEMS new materials, innovative processing and future applications. Am Ceram Soc Bull. 2001;80(5):25-30.

18. Biesuz M, Zera E, Tomasi M, et al. Polymer-derived $\mathrm{Si}_{3} \mathrm{~N}_{4}$ nanofelts for flexible, high temperature, lightweight and easy-manufacturable superthermal insulators. Appl Mater Today. 2020;20:100648. https://doi.org/10.1016/j.apmt.2020.100648

19. Biesuz M, Tomasi M, Santhosh B, Sglavo VM, Sorarù GD. Polymer-derived $\mathrm{Si}_{3} \mathrm{~N}_{4}$ nanofelts as a novel oil spills clean-up architecture. J Environ Chem Eng. 2020;8(5):104134. https://doi. org/10.1016/j.jece.2020.104134

20. Janakiraman N, Aldinger F. Fabrication and characterization of fully dense Si-C-N ceramics from a poly(ureamethylvinyl)silazane precursor. J Eur Ceram Soc. 2009;29(1):163-73. https://doi. org/10.1016/j.jeurc erams oc.2008.05.028

21. Rouxel T, Massouras G, Sorarù GD. High temperature behavior of a gel-derived SiOC glass: Elasticity and viscosity. J Sol-Gel Sci Technol. 1999;14(1):87-94. https://doi.org/10.1023/A:10087 79915809 
22. Stabler C, Ionescu E, Gonzalo-juan I, Graczyk-zajac M, Riedel R. Silicon oxycarbide glasses and glass - ceramics : "All - Rounder" materials for advanced structural and functional applications. J Am Ceram Soc. 2018;101(11):4817-56. https://doi.org/10.1111/ jace.15932

23. Riedel R, Ruswisch LM, An L, Raj R. Amorphous silicoboron carbonitride ceramic with very high viscosity at temperatures above $1500^{\circ} \mathrm{C}$. J Am Ceram Soc. 1998;81(12):3341-4. https://doi. org/10.1111/j.1151-2916.1998.tb027 80.x

24. Corriu RJP, Leclercq D, Mutin PH, Vioux A. Preparation and structure of silicon oxycarbide glasses derived from polysiloxane precursors. J Sol-Gel Sci Technol. 1997;8:327-30.

25. Saha A, Raj R, Williamson DL. A model for the nanodomains in polymer-derived SiCO. J Am Ceram Soc. 2006;89(7):2188-95. https://doi.org/10.1111/j.1551-2916.2006.00920.x

26. Widgeon SJ, Sen S, Mera G, Ionescu E, Riedel R, Navrotsky A. ${ }^{29} \mathrm{Si}$ and ${ }^{13} \mathrm{C}$ solid-state NMR spectroscopic study of nanometer-scale structure and mass fractal characteristics of amorphous polymer derived silicon oxycarbide ceramics. Chem Mater. 2010;22(23):6221-8. https://doi.org/10.1021/cm102 1432

27. Mera G, Navrotsky A, Sen S, Kleebe HJ, Riedel R. Polymer-derived SiCN and SiOC ceramics-structure and energetics at the nanoscale. J Mater Chem A. 2013;1(12):3826-36. https://doi. org/10.1039/c2ta0 0727d

28. Sorarù GD, Dallapiccola E, D'Andrea G. Mechanical characterization of sol-gel-derived silicon oxycarbide glasses. J Am Ceram Soc. 1996;79(8):2074-80.

29. Sorarù GD, Kundanati L, Santhosh B, Pugno N. Influence of free carbon on the Young's modulus and hardness of polymer-derived silicon oxycarbide glasses. J Am Ceram Soc. 2018;102(3):907-13. https://doi.org/10.1111/jace.16131

30. Rouxel T, Soraru GD, Vicens J. Creep viscosity and stress relaxation of gel-derived silicon oxycarbide glasses. J Am Ceram Soc. 2001;84(5):1052-8. $\quad$ https://doi.org/10.1111/j.1151-2916.2001. tb007 89.x

31. Shah SR, Raj R. Mechanical properties of a fully dense polymer derived ceramic made by a novel pressure casting process. Acta Mater. 2002;50(16):4093-103. https://doi.org/10.1016/S1359 -6454(02)00206 -9

32. Narisawa M, Funabiki F, Iwase A, Wakai F, Hosono H. Effects of atmospheric composition on the molecular structure of synthesized silicon oxycarbides. J Am Ceram Soc. 2015;10:3373-80. https:// doi.org/10.1111/jace.13756

33. Graczyk-Zajac M, Vrankovic D, Waleska P, et al. The Li-storage capacity of SiOC glasses with and without mixed silicon oxycarbide bonds. J Mater Chem A. 2017;6(1):93-103. https://doi. org/10.1039/c7ta0 9236a

34. Nguyen VL, Zera E, Perolo A, Campostrini R, Li W, Sorarù GD. Synthesis and characterization of polymer-derived SiCN aerogel. J Eur Ceram Soc. 2015;35:3295-302. https://doi.org/10.1016/j.jeurc erams oc.2015.04.018

35. Blum Y, Sorarù GD, Ramaswamy AP, Hui D, Carturan SM. Controlled mesoporosity in SiOC via chemically bonded polymeric "spacers". J Am Ceram Soc. 2013;96(9):2785-92. https:// doi.org/10.1111/jace.12485

36. Sorar GD, Campostrini R, Maurina S, Babonneau F. Gel pre-cursor to silicon oxycarbide glasses with ultrahigh ceramic yield. J Am Ceram Soc. 2005;80(4):999-1004. https://doi. org/10.1111/j.1151-2916.1997.tb029 33.x

37. Assefa D, Zera E, Campostrini R, Soraru GD, Vakifahmetoglu C. Polymer-derived SiOC aerogel with hierarchical porosity through HF etching. Ceram Int. 2016;42:11805-9. https://doi.org/10.1016/j. ceram int.2016.04.101

38. Zera E, Nickel W, Hao GP, Vanzetti L, Kaskel S, Sorarù GD. Nitrogen doped carbide derived carbon aerogels by chlorine etching of a SiCN aerogel. J Mater Chem A. 2016;4(12):4525-33. https://doi.org/10.1039/c6ta0 0589f

39. Zera E, Nickel W, Kaskel S, Sorarù GD. Out-of-furnace oxidation of SiCN polymer-derived ceramic aerogel pyrolized at intermediate temperature (600-800 $\left.{ }^{\circ} \mathrm{C}\right)$. J Eur Ceram Soc. 2016;36(3):423-8. https://doi.org/10.1016/j.jeurc erams oc.2015.10.038

40. Janakiraman N, Aldinger F. Indentation analysis of elastic and plastic deformation of precursor-derived Si-C-N ceramics. J Eur Ceram Soc. 2010;30:775-85. https://doi.org/10.1016/j.jeurc erams oc.2009.09.006

41. Lawn B. Fracture of brittle solids, 2nd edn. New York, NY: Cambridge University Press; 1993.

42. Arora A, Marshall DB, Lawn BR. Indentation deformation/fracture of normal and anomalous glasses. J Non Cryst Solids. 1979;31:415-28.

43. Kurkjian CR, Kammlott GW, Chaudhri MM. Indentation behaviour of soda-lime silica glass, fused silica, amd single-crystal quartz at liquid nitrogen temperature. J Am Ceram Soc. 1995;78:737-44.

44. Walter S, Soraru GD, Bréquel H, Enzo S. Microstructural and mechanical characterization of sol gel-derived Si-O-C glasses. J Eur Ceram Soc. 2002;22(13):2389-400. https://doi.org/10.1016/S0955 -2219(01)00537 -4

45. Moysan C, Riedel R, Harshe R, Rouxel T, Augereau F. Mechanical characterization of a polysiloxane-derived SiOC glass. J Eur Ceram Soc. 2007;27:397-403. https://doi.org/10.1016/j.jeurc erams oc.2006.01.016

46. Rouxel T. Elastic properties and short-to medium-range order in glasses. J Am Ceram Soc. 2007;90(10):3019-39.

47. Belot V, Corriu R, Leclercq D, Mutin PH, Vioux A. Thermal reactivity of hydrogensilsequioxane gels. Chem Mater. 1991;3:127-31.

48. Soraru GD, D’Andrea G, Campostrini R, Babonneau F.

Characterization of methyl-substituted silica gels with Si-H functionalities. J Mater Chem. 1995;1363-74.

49. Bahloul D, Pereira M, Goursat P, Yive NSCK, Corriu RJP. Preparation of silicon carbonitrides from an organosilicon polymer: I, thermal decomposition of the cross-linked polysilazane. J Am Ceram Soc. 1993;76(5):1156-62. https://doi. org/10.1111/j.1151-2916.1993.tb037 34.x

50. Schmidt H, Koch D, Grathwohl G, Colombo P. Micro-/ macroporous ceramics from preceramic precursors. J Am Ceram Soc. 2001;84(10):22525 .

51. Suyal N, Krajewski T, Mennig M. Sol-gel synthesis and microstructural characterization of silicon oxycarbide glass sheets with high fracture strength and high modulus. J Sol-Gel Sci Technol. 1998;13:995-9. 
52. Sorarù GD, Karakuscu A, Boissiere C, Babonneau F. On the shrinkage during pyrolysis of thin films and bulk components: The case of a hybrid silica gel precursor for SiOC glasses. J Eur Ceram Soc. 2012;32(3):627-32. https://doi.org/10.1016/j.jeurc erams oc.2011.10.004

53. Raj R, Pederiva L, Narisawa M, Soraru GD. On the onset of fracture as a silicon-based polymer converts into the ceramic phase. J Am Ceram Soc. 2019;102(3):924-9. https://doi.org/10.1111/ jace.16089

54. Bor B, Giuntini D, Domènech B, Swain MV, Schneider GA. Nanoindentation-based study of the mechanical behavior of bulk supercrystalline ceramic-organic nanocomposites. J Eur Ceram Soc. 2019;39:3247-56. https://doi.org/10.1016/j.jeurc erams oc.2019.03.053

\section{SUPPORTING INFORMATION}

Additional supporting information may be found online in the Supporting Information section.

How to cite this article: Sorarù GD, Tavonatti C, Kundanati L, Pugno N, Biesuz M. Effect of the pyrolysis atmosphere on the mechanical properties of polymer-derived SiOC and SiCN. J Am Ceram Soc. 2020;103:6519-6530.

https://doi.org/10.1111/ jace.17392 